\title{
A Secure Based Preserving Social Media Data Management System
}

\author{
V. Geetha, C.K.Gomathy, Kopparapu Sai Charan, Mandadi Koushik
}

\begin{abstract}
Personalized suggestions are important to help users find relevant information. It often depends on huge collection of user data, especially users' online activity (e.g., liking/commenting/sharing) on social media, thereto user interests. Publishing such user activity makes inference attacks easy on the users, as private data (e.g., contact details) are often easily gathered from the users' activity data. during this module, we proposed PrivacyRank, an adjustable and always protecting privacy on social media data publishing framework, which protects users against frequent attacks while giving personal ranking based recommendations. Its main idea is to continuously blur user activity data like user-specified private data is minimized under a given data budget, which matches round the ranking loss suffer from the knowledge blurring process so on preserve the usage of the info for enabling suggestions. a true world evaluation on both synthetic and real-world datasets displays that our model can provide effective and continuous protection against to the info given by the user, while still conserving the usage of the blurred data for private ranking based suggestion. Compared to other approaches, Privacy Rank achieves both better privacy protection and a far better usage altogether the rank based suggestions use cases we tested.
\end{abstract}

Keywords: Privacy preserving, Adjustable privacy protection, Rank based suggestion.

\section{INTRODUCTION}

$\mathrm{O}$ nline selling platform has led to a fundamental change within the way that companies interact with their customers. most the famous platforms, like Taobao and Amazon, plan to attract new customers or to stay existing customers by developing good strategies to suggest products. Conventional suggestions usually use content based, collaborative filter based or hybrid methods. of these functions essentially group users into different

Manuscript received on April 12, 2021.

Revised Manuscript received on April 26, 2021.

Manuscript published on April 30, 2021.

* Correspondence Author

Dr. V. Geetha, Assistant Professor in CSE Department, SCSVMV Deemed to be University

Dr. C.K. Gomathy*, Assistant Professor in CSE Department, SCSVMV Deemed to be University

Mr. Maddu Pavan Manikanta Kiran, UG Scholar CSE Department, SCSVMV Deemed to be University

Mr. Gandikota Rajesh, UG Scholar CSE Department, SCSVMV Deemed to be University

(C) The Authors. Published by Blue Eyes Intelligence Engineering and Sciences Publication (BEIESP). This is an open access article under the CC BY-NC-ND license (http://creativecommons.org/licenses/by-nc-nd/4.0/) groups and make suggestions supported the grouping information. However, a recent survey shows that $84 \%$ consumers' purchase behaviours are strongly influenced by friends' behaviours or friends' recommendations. Exploiting the trust relationships between customers can significantly help E-Commerce. This actually has been demonstrated by social recommendation, which suggests that the recommendation performances are often significantly improved with trust relationships. However, social suggestion doesn't present successful applications in industry. for instance, consistent with IBM's Black Friday report, social networks like Facebook, Instagram and Twitter only contribute $0.34 \%$ of all online sales on Black Friday. one among the main challenges for using social suggestions to several E-Commerce platforms is that there's no trust relationships are available. Online social networks like Facebook and Twitter record many different kinds of social relationships, but not all relationships are trustful.

\section{LITERATURE SURVEY}

To protect user private data when publishing user information, the prevailing systems mainly depends on policies or user agreements .Example on the utilization and storage of the published data. However, there's no guarantee on this approach that the users' private information is really shielded from different attackers. In order, to supply effective privacy protection while publishing user data, privacy preserving data publishing has been extensively studied. The second category is especially supported theory and focuses on the Non-informative principle, i.e.,the published data should provide attackers with as little private information as possible beyond background .Differential privacy a well-known technique which is understood to supply user privacy against attackers with additional background . we've also proposed Information-theoretic privacy protection approach therein context. They continuously attempt to measure privacy leakage mainly on various entropy-based metrics like conditional entropy and to style privacy-protection mechanisms supported those measures.

\section{PROPOSED METHODOLOGY}

Published By:

Blue Eyes Intelligence Engineering 
The system has began to collect problem of consisting an outsized number of user interests like search history, mobile records, GPS information, etc. The system having some relationships acknowledged with differing types of trust or distrust by users or outsiders and its goal is to infer all the other trust and distrust relationships. one among the Effective thanks to train a supervised model by viewing each relationship as an instance. for instance, within the proposed system, the model should understand that if two persons are staying at an equivalent location it means they need some relationship.

\section{SYSTEM ARCHITECTURE}

This Paper Investigates The Way To Effectively Leverage Network Correlations To Infer Trust Relationships When An Outsized Number Of Neighbouring Relationships Are Unlabelled. To Deal With The Challenge of Limited Labelled Relationships, Semi Supervised Learning Like Label Propagation Could Help, By Iteratively Propagating Trust Scores From Labelled Relationships To Unlabelled Relationships. However, Direct Communication Isn't Always Productive, Thanks To The Difficult Semantics Of Trust Relationships. For Instance In Figure 1, Mary Doesn't Know Ruby's Colleague Lucy, Allow Us To Think Lucy Is Alone. In Summary, These Contributions Of Labor Are Often Summarized As: We Categorized Trust Into Fine-Grained Types, And Investigate Potential Useful Correlations.

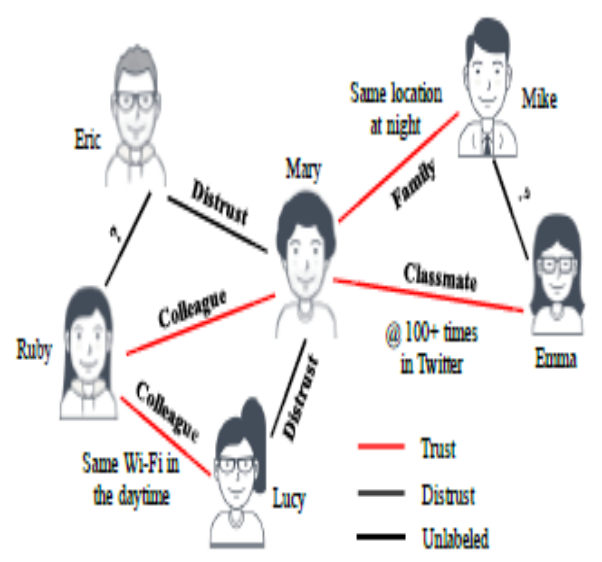

Figure 1: System Architecture

\section{WORKING MODEL}

Functionalities of both the applications are always related in one or Mode ways. This system has many functionalities namely
oAdmin module
o Seller Module
o Buyer Module
o Social Media Communication Module
o Recommendation module

Each of these functionalities are having their own importance in the whole system working.

Admin module - Login: To Login into this module we need to get the username and password from the authorized administrator of e-commerce and social media.
Add Categories: In order to add new categories of products to the e-commerce site from this module, the administrator is only authorized.

Add Products: The administrator is the only person who can add new products are to the ecommerce site under a pre-defined category in this module.

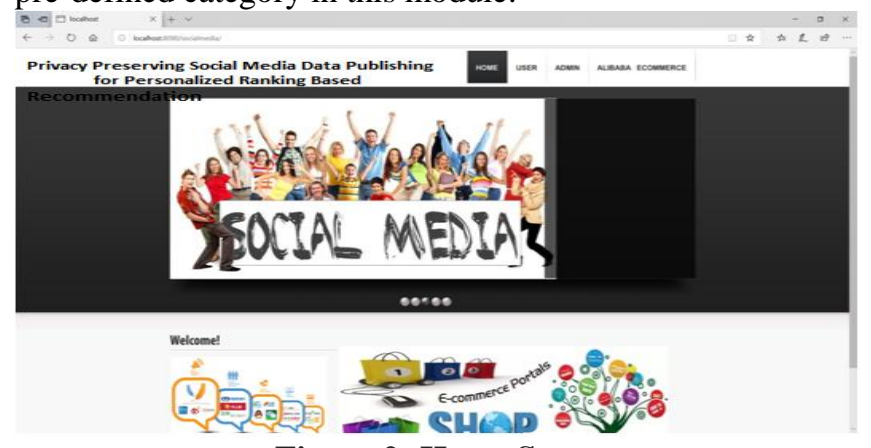

Figure 2: Home Screen

View User: The administrator can view and authorize the registered social media users in this module. The profile of the user along with the purchase history can be viewed here. View History: The administrator can view the search made by the registered user in this module.

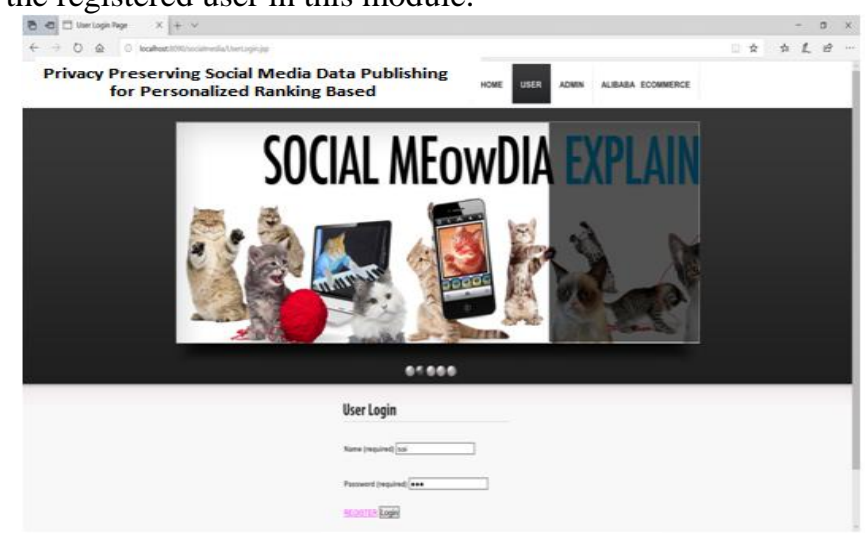

Figure 3: Login Screen

> Seller Module - Seller Module provides various activities described below

$>$ Maintains of Products : this provides to maintain products in website

$>$ Promote Brands : This provides to maintain various brands in ecommerce

$>$ Promote Discounts : This provides various discounts for products

$>$ Provide Combination of Products: Provides Combinations for products

$>$ Provide Combination Offers : Provides various combinations for products

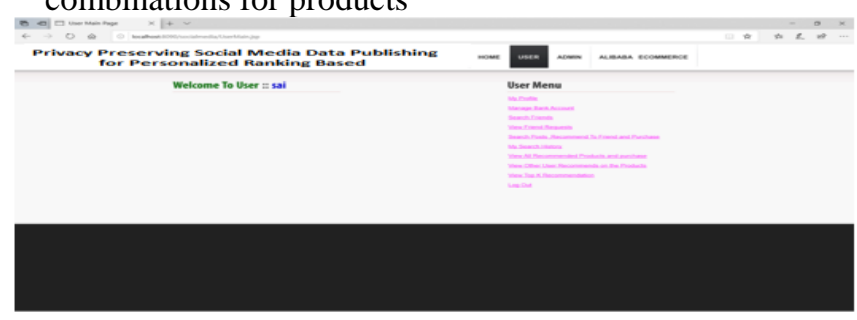

Figure 4: User Menu

Buyer Module - Buyer Module provides various activities described below

Published By:

Blue Eyes Intelligence Engineering

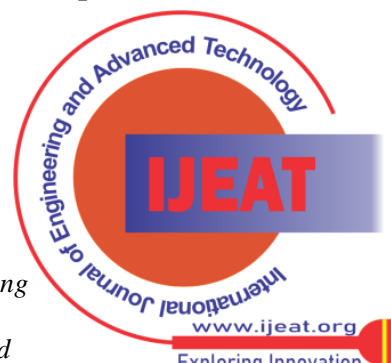
Exploring Innovation 
$>$ Registration: Provides Registration for User to get user id and password.

$>$ Login: Provides login to users to login into ecommerce website

$>$ Search of Products: provides search of products

$>$ View Products: provides view of products

$>$ Bargain for Price: provides Bargain to Products

$>$ View Combination Offers: Reports to view various combinations of products

$>$ View willing Price Vendors List: Reports to view various willing list
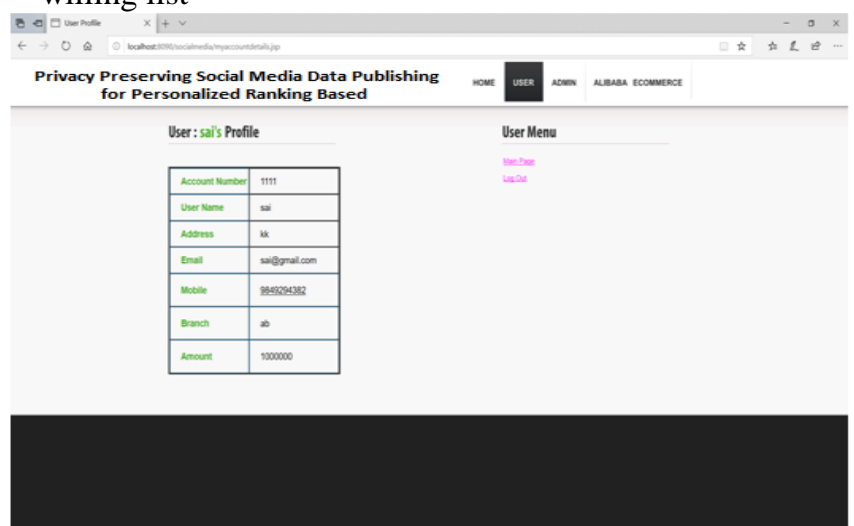

\section{Search Friend}

Figure 5: User Profile

In this module the users can search and find their friends they are looking for in the social media, only if they have registered in the same media.
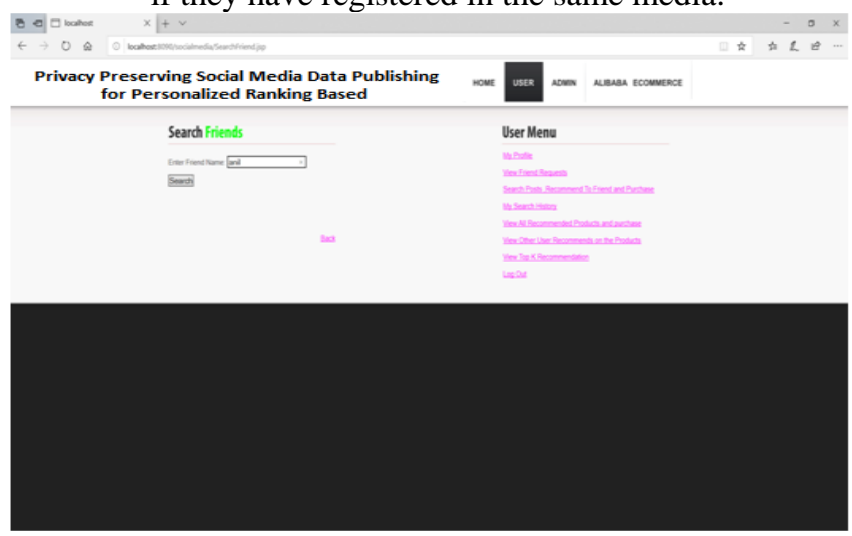

Figure 6: Searching Friends
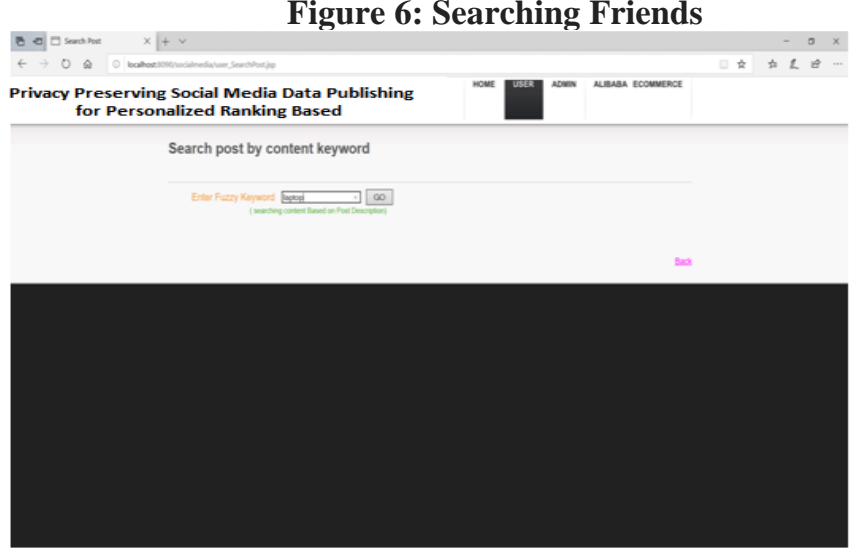

Figure 8: Search post by content
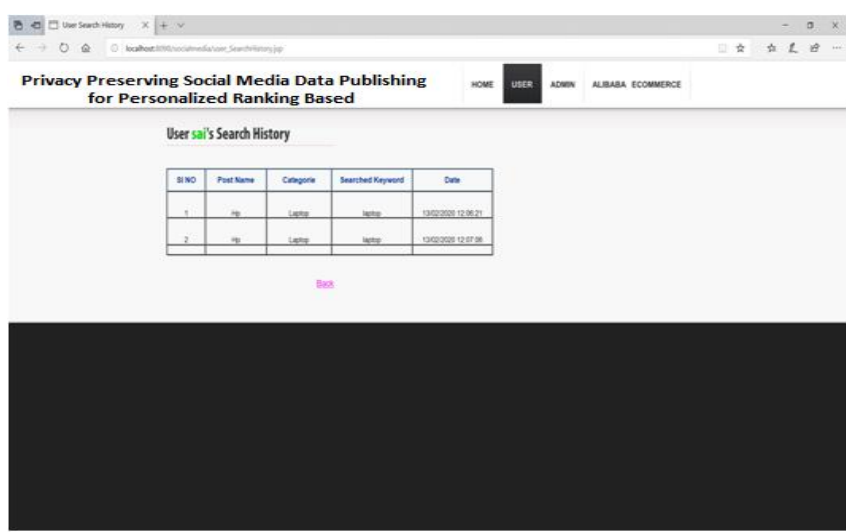

Figure 9: User History

- POST RECOMMENDATION: The product recommendations can be made to their friends on social media by the registered users.
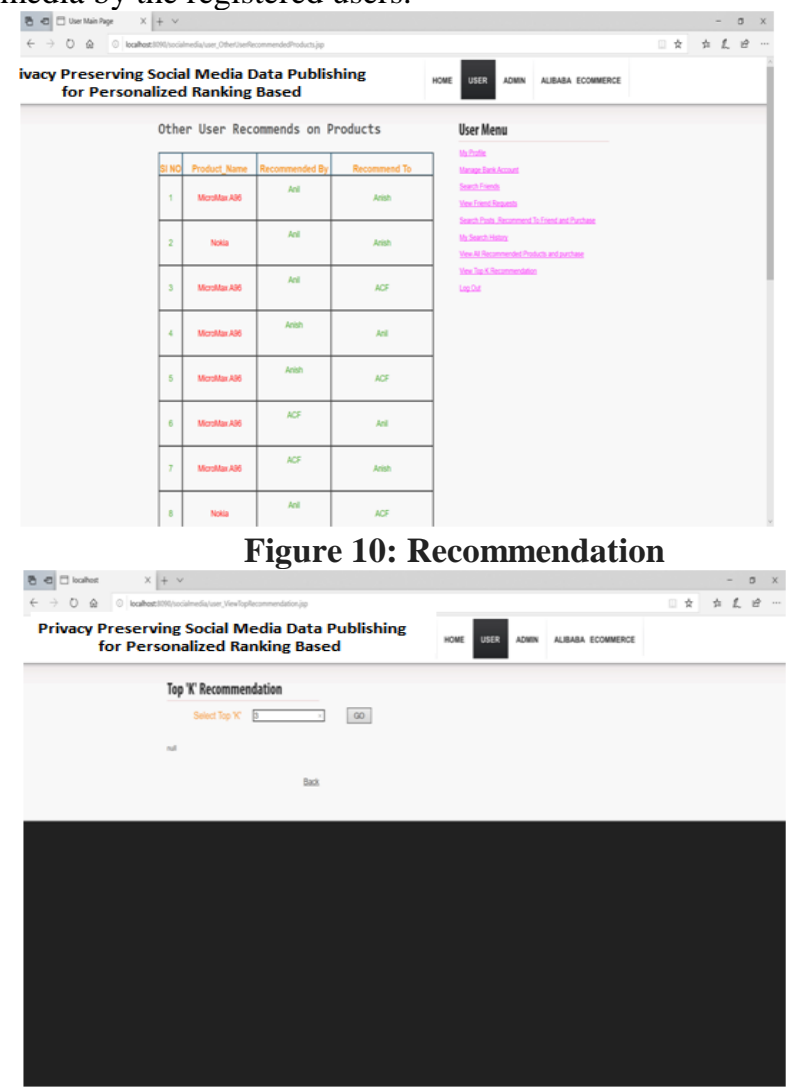

Figure 11: Top Recommendation

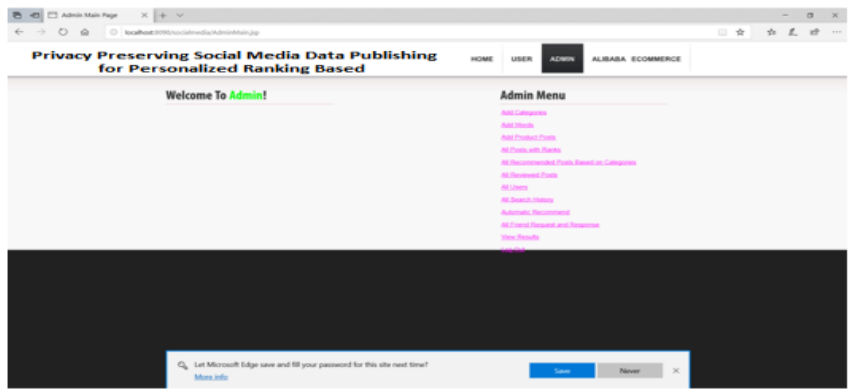

Figure 12: Admin Menu

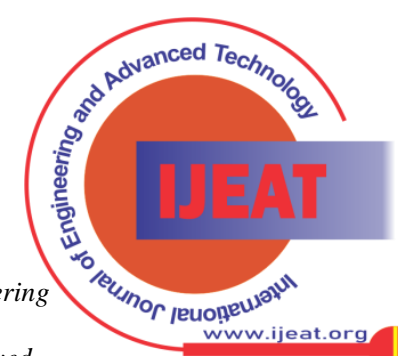




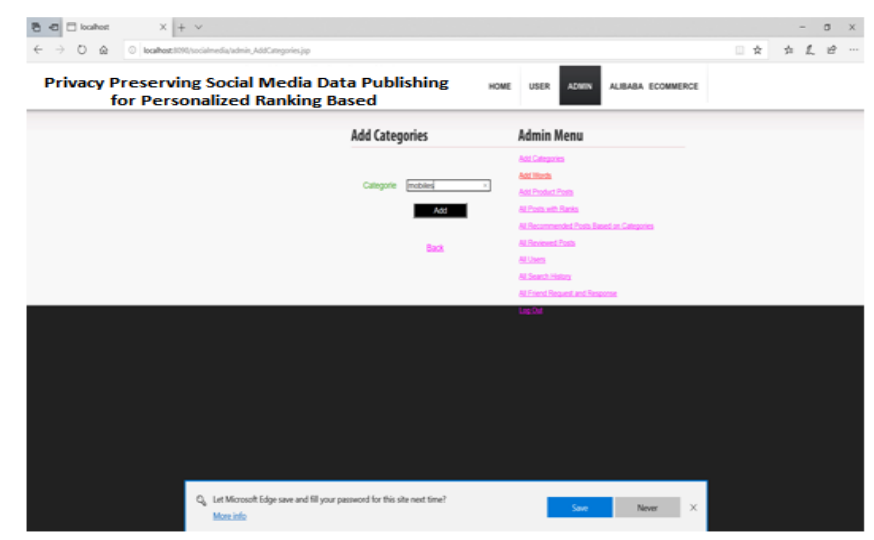

Figure 13: Adding Categories

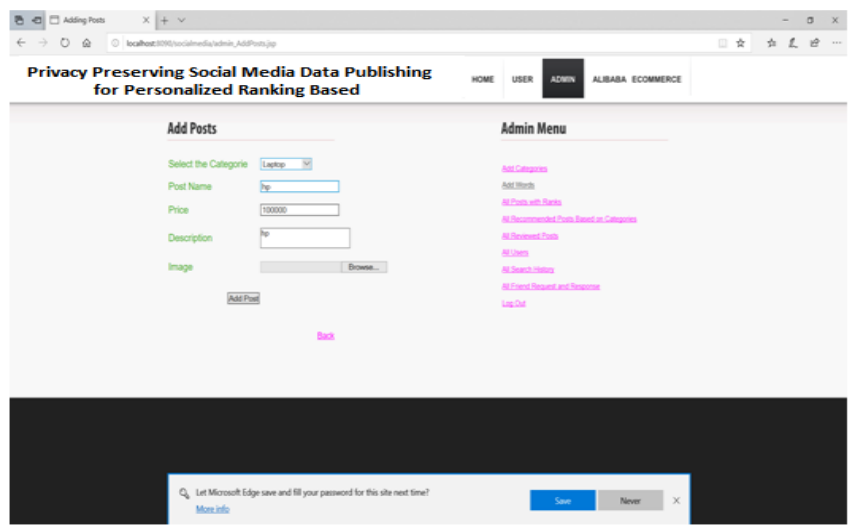

Figure 14: Adding posts

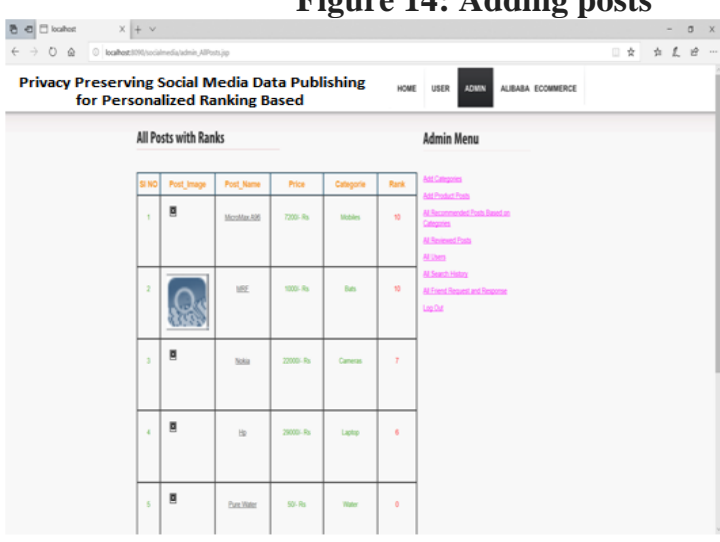

Figure 15: All posts with Ranks

\section{CONCLUSION}

This Project introduced Privacy Rank, an adjustable and always preserving privacy on social media data publishing framework. It always protects the data that is specified by the user against inference attacks by publishing blurred user activity data, while still ensuring the usage of the published data to power personal rank based suggestions. Even through these extensive experiments we showed that Privacy Rank can guarantee an efficient protection of private data, while it still preserves the usage of the published data for different rank based recommendation use cases.

\section{REFERENCES}

1. B. Fung, K. Wang, R. Chen, and P. S. Yu, "Privacy-preserving data publishing: A survey of recent developments," ACM Computer Survey, vol. 42, no. 4, p. 14, 2018.
2. A. Machanavajjhala, D. Kifer, J. Gehrke, and M. Venkitasubramaniam, "1-diversity: Privacy beyond -anonymity," ACM Transactions on Knowledge Discovery from Data, vol. 1, no. 1, p. 3, 2017.

3. C. Dwork, "Differential privacy," in Automata, languages and programming. Springer, 2016, pp. 1-12

4. L. Backstrom and J. Leskovec. Supervised random walks: predicting and recommending links in social networks. In Proceedings of $4^{\text {th }}$ ACM International Conference on Web Search and web Data Mining, pages 635-644, 2011.

5. D. Crandall, D. Cosley, D. Huttenlocher, J. Kleinberg, and S. Suri. Feedback effects between similarity and social influence in online communities. In Proceedings of the 14th ACM SIGKDD international conference on Knowledge discovery and data mining, pages 160-168, 2008.

6. C K Gomathy and V Geetha. Article: A Real Time Analysis of Service based using Mobile Phone Controlled Vehicle using DTMF for Accident Prevention. International Journal of Computer Applications 138(2):11-13, March 2016. Published by Foundation of Computer Science (FCS), NY, USA,ISSN No: 0975-8887

7. Dr.C.K.Gomathy, K. Bindhu sravya, P. Swetha, S.Chandrika Article: A Location Based Value Prediction for Quality of Web Service, Published by International Journal of Advanced Engineering Research and Science (IJAERS), Vol-3, Issue-4 , April- 2016] ISSN: 2349-6495

8. C.K.Gomathy.(2010),"Cloud Computing: Business Management for Effective Service Oriented Architecture" International Journal of Power Control Signal and Computation (IJPCSC), Volume 1, Issue IV, Oct - Dec 2010, P.No:22-27, ISSN: 0976-268X.

9. Dr.C K Gomathy, Article: A Semantic Quality of Web Service Information Retrieval Techniques Using Bin Rank, International Journal of Scientific Research in Computer Science Engineering and Information Technology ( IJSRCSEIT ) Volume 3 | Issue 1 | ISSN : 2456-3307, P.No:1563-1578, February-2018

10. Dr.C K Gomathy, Article: A Scheme of ADHOC Communication using Mobile Device Networks, International Journal of Emerging technologies and Innovative Research ( JETIR ) Volume 5 | Issue 11 ISSN : 2349-5162, P.No:320-326, Nov-2018.

11. Dr.C K Gomathy, Article: Supply chain-Impact of importance and Technology in Software Release Management, International Journal of Scientific Research in Computer Science Engineering and Information Technology ( IJSRCSEIT ) Volume 3 | Issue 6 | ISSN : 2456-3307, P.No:1-4, July-2018

12. C.K. Gomathy, V. Geetha, Venkata Nagendra, Venkata Sai Ram, Article: The Secured Proficient Smart Electronic Voting System, International Journal of Engineering and Advanced Technology (IJEAT) ISSN: 2249 - 8958, Volume-9 Issue-4, April 2020

13. V.Geetha, C.K.Gomathy, P.Manojkumar, N.S.L.S.V.Manohar, Article: The Sentimental Analysis for E-Commerce Application, International Journal of Engineering and Advanced Technology (IJEAT) ISSN: 2249 - 8958, Volume-9 Issue-5, June 2020

14. CKGomathy,V Geetha,P.S.lavakumar,K.V.Rahul,The Efficient Automatic Water Control Level Management Using Ultrasonic Sensor, International Journal of Computer Applications (0975 - 8887) Volume 176 - No. 39, July 2020

15. V. Geetha, C.K. Gomathy, Maddu Pavan Manikanta Kiran, Gandikota Rajesh, The Implementation of Fleet Monitoring System using Mobile based Software, International Journal of Engineering and Advanced Technology (IJEAT) ISSN: 2249 - 8958, Volume-9 Issue-4, April 2020

16. C K Gomathy, Student Location Tracking inside College Infrastructure, International Research Journal of Engineering and Technology (IRJET) e-ISSN: 2395-0056 Volume: 07 Issue: 06 | June 2020

\section{AUTHORS PROFILE}

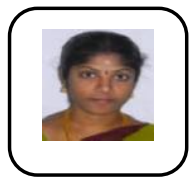

Dr. V.Geetha, is assistant professor in computer science and engineering at SCSVMV, Kanchipuram, India. Her area of interest lies in Java Programming, Software Quality Assurance, Computer System Architecture Domain.

Published By: Blue Eyes Intelligence Engineering \& Sciences Publication C Copyright: All Rights Reserved

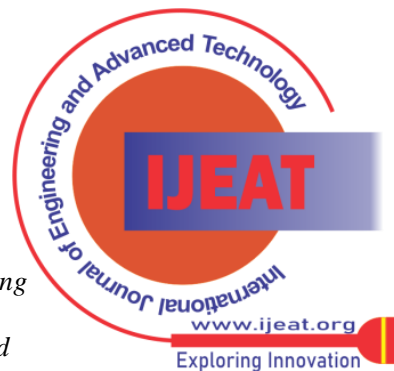




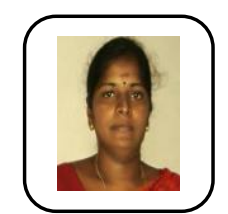

Dr. C.K.Gomathy, is Assistant Professor in CSE at Sri Chandrashekarendra Saraswathi Viswa Mahavi dyalaya deemed to be university, Enathur, Kanchipuram, India. Her area of Intrest is Software Engineering Web Services, Knowledge Management and IOT.

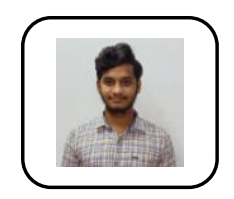

Kopparapu Sai Charan, student, B.E. Computer Science and Engineering, SCSVMV.

Mandadi Koushik, student, B.E. Computer Science and Engineering, SCSVMV.

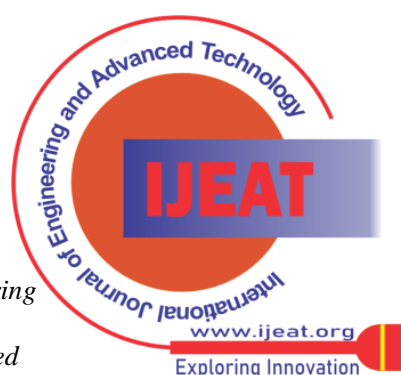

